\title{
Prof. Dr. Antonio Dorival Campos
}

31/05/1937 - 19/07/2009

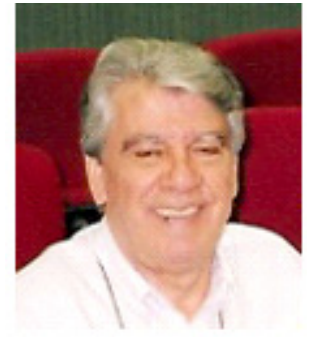

Antonio Dorival Campos, tado de São Paulo em 31 de maio de 1937. Iniciou o curso primário em Catanduva-SP e o concluiu em Pindorama-SP. Fez o curso ginasial e o científico no Instituto de Educação Estadual Barão de Rio Branco em Catanduva e ingressou no curso de Licenciatura em Matemática na Faculdade de Filosofia, Ciências e Letras da Universidade de São Paulo no ano de 1957, graduando-se em 13 de março de 1961.

Em maio de 1961 ingressou na carreira universitária, como auxiliar de ensino junto ao Departamento de Matemática da Faculdade de Filosofia, Ciências e Letras de Rio Claro, então Instituto Isolado de Ensino Superior, que mais tarde passou a integrar a Universidade Estadual Paulista Júlio de Mesquita Filho.

Durante os anos de 1964 e 1965 cursou o Mestrado em Estatística Matemática pelo CIENES (Centro Interamericano de Enseñanza de Estadistica) em Santiago, Chile, com bolsa da OEA (Organização dos Estados Americanos) tendo sido um dos primeiros matemáticos brasileiros a obter tal titulação.

Em 1967 passou a fazer parte do corpo docente da Faculdade de Medicina de Ribeirão Preto da Universidade de São Paulo (FMRP-USP), Departamento de Matemática Aplicada à Biologia. Obteve o título de doutor pela FMRP-USP em 16 de outubro de 1971, apresentando tese intitulada "Extensão de algumas desigualdades usadas para a determinação de estimadores não viciados e uniformemente de variância mínima". Foi professor visitante junto à Faculdade de Filosofia, Ciências e Letras de São José de Rio Preto-SP, no ano de 1971, ministrando disciplinas de
Probabilidade e Inferência a alunos da graduação em Matemática. Em 1980, obteve o título de livre Docente da Universidade de São Paulo, apresentando a tese "Afinidade de funções distribuições multivariadas de uma mesma classe". Em 1987 foi aprovado em concurso público obtendo o título de Professor Adjunto do Departamento de Genética e Matemática Aplicada à Biologia da FMRPUSP. Teve intensa atividade como pesquisador de Estatística com diversos trabalhos publicados, viagens de estudo ao exterior, participação em congressos e como consultor na área de Bioestatística. Atuou como docente e orientador no programa de pós-graduação em Bioestatística, que funcionou na Faculdade de Medicina de Ribeirão Preto desde o ano de 1970 até o ano de 1998 e no Programa de Pós-graduação "Ciências de Computação e Estatística" da Área Inter Unidades da Universidade de São Paulo (FMRP-USP e Instituto de Ciências Matemáticas de São Carlos) de 1976 a 1979.

A partir de 2000, passou a fazer parte do Departamento de Medicina Social da Faculdade de Medicina de Ribeirão Preto, continuando a atuar na área de Estatística, prestando consultorias aos profissionais da saúde da instituição e colaborando em alguns programas de pós-graduação em Medicina.

Era sócio da Associação Brasileira de Estatística desde sua fundação e participou de todos os SINAPE-s até o ano de sua aposentadoria, que se deu em maio de 2007, Era também sócio da Sociedade Internacional de Biometria. Faleceu em São Paulo, em 19 de julho de 2009. Deixou a esposa, Clair, quatro filhas e seis netos.

\section{Profa. Dra . MARIA APARECIDA DE PAIVA FRANCO} Departamento de Estatística

Centro de Ciências Exatas e de Tecnologia. UFSCar 